\title{
TOAST subtypes: its influence upon doctors' decisions of antihypertensive prescription at discharge for ischemic stroke patients
}

This article was published in the following Dove Press journal:

Patient Preference and Adherence

14 December 2012

Number of times this article has been viewed

Jie $\mathrm{Xu}^{*}$

Liping Liu*

Yilong Wang

Xingquan Zhao

Chunxue Wang

Anxin Wang

Yongjun Wang

Department of Neurology, Beijing Tiantan Hospital, Capital Medical

University, Beijing, China

*These authors contributed equally to this work
Correspondence: Yongjun Wang Department of Neurology, Beijing Tiantan Hospital, Capital Medical University, No 6 Tiantanxili, Dongcheng District, Beijing, China, 100050

Tel +860I0 67098350

Fax +8601067013383

Email yongjunwangI I I@yahoo.com.cn
Aim: To investigate the influence of the Trial of Org 10172 in Acute Stroke Treatment (TOAST) subtypes in doctors' decisions to use antihypertensive prescriptions at discharge for ischemic stroke patients in a real-world setting.

Methods: Using the China National Stroke Registry, we analyzed data from 12,063 hospitalized patients who had been diagnosed with ischemic stroke. The cause of ischemic stroke was classified according to the TOAST criteria. The information about the prescription of antihypertensive medication at discharge was extracted from medical records. Multivariate logistic regression was used to assess the impact of TOAST subtypes on the prescription of antihypertensive medication at discharge.

Results: Multivariate analysis showed that, compared with large artery atherosclerosis patients with moderate $(<70 \%)$ stenosis, large artery atherosclerosis patients with severe $(\geq 70 \%)$ stenosis or patients with stroke of undetermined etiology were less likely to be prescribed antihypertensive medication at discharge (odds ratio [OR], 0.72; 95\% confidence interval [CI]: 0.59-0.88; OR, 0.71; 95\% CI: 0.64-0.79), while patients with small artery occlusion were more likely to be prescribed antihypertensives (OR, 1.50; 95\% CI: 1.33-1.69).

Conclusion: The TOAST subtype is an important determinant of the prescription of antihypertensive medication for ischemic stroke patients at discharge in normal clinical practice.

Keywords: antihypertensive agents, ischemic stroke, TOAST classification

\section{Introduction}

Antihypertensive treatment is recommended for secondary prevention in ischemic stroke patients with or without a documented history of hypertension by current American Heart Association/American Stroke Association guidelines. ${ }^{1}$ However, in normal clinical practice, the mechanisms of ischemic stroke may have influenced doctors' decisions to initiate antihypertensive therapies, particularly in patients with severe stenosis or occlusion in intracranial or extracranial arteries, or with nonatherosclerotic mechanisms such as hypercoagulable states, vasculitis, and so on. In this study, we investigated the influence of Trial of Org 10172 in Acute Stroke Treatment (TOAST) subtype on doctors' decisions to use antihypertensive prescriptions at discharge for ischemic stroke patients in a real-world setting.

\section{Methods}

Patient data were obtained from the China National Stroke Registry (CNSR), a nationwide, prospective cohort study aimed at identifying vascular risk factors, and documenting the clinical characteristics, diagnosis, and treatments for patients with acute stroke. 
The detailed protocol of the CNSR has been published elsewhere. ${ }^{2}$ Between September 2007 and August 2008, all consecutive stroke patients aged 18 years or older who were admitted to 132 hospitals within 14 days after the onset of symptoms were recruited. The collection of data for the CNSR was approved by ethics committees at the participating hospitals. Written informed consent was obtained from the patient or his/her legally authorized representative.

The cause of ischemic stroke was classified according to the TOAST criteria, ${ }^{3}$ including large artery atherosclerosis (LAA); small artery occlusion (SAO); cardioembolism (CE); stroke of other determined etiology (SOE); and stroke of undetermined etiology (SUE). In this study, LAA patients were further divided into two groups: moderate stenosis ( $<70 \%$ stenosis in intracranial or extracranial arteries) and severe stenosis ( $\geq 70 \%$ ). The information about the prescription of antihypertensive medication at discharge was extracted from medical records. Classes of antihypertensive medication included angiotensin-converting enzyme inhibitors, angiotensin receptor blockers, calcium channel blockers, diuretics, beta-blockers, and other antihypertensives including centrally acting adrenergics, peripherally acting antiadrenergics, and vasodilators.

\section{Statistical analysis}

Univariate and multivariate logistic regression analyses were used to calculate the crude and adjusted odds ratios (ORs), respectively, for the association between TOAST subtypes and the prescription of antihypertensive medication at discharge. The multivariate models were created using variables associated with antihypertensive medication prescription (gender, age, monthly household income, types of health insurance, hypertension, diabetes mellitus, dyslipidemia, coronary heart disease, atrial fibrillation, history of stroke, previous antihypertensive medication use, and systolic blood pressure at discharge). Effect sizes were expressed as ORs and 95\% confidence intervals (CIs). Two-tailed statistical significance was defined as $P<0.05$. All statistical analyses were performed using SAS 9.1.3 (SAS Institute Inc, Cary, NC, USA).

\section{Results}

\section{Patients' characteristics}

A total of 12,063 ischemic stroke patients were analyzed in this study, with a mean age at entry of $65.4 \pm 11.6$ years; $38.0 \%$ of the patients were women, $33.8 \%$ had a history of stroke, $70.8 \%$ had hypertension, $28.0 \%$ had diabetes, and $55.0 \%$ had dyslipidemia (Table 1). Among all ischemic stroke subjects with or without hypertension, 4742 patients $(39.3 \%)$ received a prescription at discharge for any antihypertensive, among whom $14(0.3 \%)$ were discharged on four or more antihypertensive agents, 266 (5.6\%) were discharged on three, 949 (20.0\%) on two, and 3513 (74.1\%) on one.

\section{Influence of TOAST subtype upon}

\section{antihypertensive prescription at discharge}

The multivariate analysis showed that when compared with LAA patients with moderate $(<70 \%)$ stenosis, the adjusted ORs with 95\% CIs were 0.72 (0.59-0.88), 1.50 (1.33-1.69), $0.91(0.72-1.15), 1.49(0.95-2.32)$, and $0.71(0.64-0.79)$ in LAA patients with severe ( $\geq 70 \%)$ stenosis, $\mathrm{SAO}, \mathrm{CE}, \mathrm{SOE}$, and SUE patients, respectively (Table 1).

\section{Other predictors of antihypertensive prescription at discharge}

Multivariate analysis showed that patients with hypertension, diabetes, dyslipidemia, high income, urban employee health insurance, and high systolic blood pressure at discharge were more likely to be prescribed with antihypertensive medication at discharge; however, the elderly were less likely to be prescribed (Table 1).

\section{Subgroup analyses}

We also investigated the influence of the TOAST subtype on antihypertensive prescription at discharge in patients with hypertension. The multivariate analysis showed that when compared with LAA patients with moderate $(<70 \%)$ stenosis, the adjusted ORs with 95\% CI were $0.70(0.57-0.86)$, 1.57 (1.38-1.78), 0.89 (0.69-1.14), 1.47 (0.90-2.41), and $0.71(0.64-0.79)$ in LAA patients with severe $(\geq 70 \%)$ stenosis, SAO, CE, SOE, and SUE patients, respectively. This was similar to the group at large.

\section{Discussion}

In normal clinical practice, given the level of concern over stroke recurrence from hypoperfusion, most neurologists tend to hold conservative attitudes toward active antihypertensive treatments for ischemic stroke patients. Our results indicated that the TOAST subtype had an influence on doctors' decisions to use antihypertensive prescriptions at discharge for ischemic stroke patients in real-world settings. Doctors tend to prescribe antihypertensives for SAO patients, but they are very cautious in prescribing them for LAA patients with severe stenosis. Unfortunately, to date there are no guidelines that have given definite recommendations as to how to choose the appropriate antihypertensive treatment for patients with 
Table I Prescription of $\mathrm{AH}$ medication at discharge for ischemic stroke patients

\begin{tabular}{|c|c|c|c|c|}
\hline \multirow[t]{2}{*}{ Variables } & \multicolumn{2}{|c|}{ Prescription of AHs at discharge } & \multirow[t]{2}{*}{ Crude OR } & \multirow[t]{2}{*}{ Adjusted OR } \\
\hline & $\mathbf{n}$ & n (\%) & & \\
\hline Total & 12,063 & $4742(39.3)$ & & \\
\hline \multicolumn{5}{|l|}{ TOAST subtype } \\
\hline LAA (stenosis < 70\%) & 4885 & $2098(43.0)$ & Reference & Reference \\
\hline LAA (stenosis $\geq 70 \%$ ) & 583 & $220(37.7)$ & $0.81(0.68-0.96)$ & $0.72(0.59-0.88)$ \\
\hline SAO & 2076 & $1050(50.6)$ & $1.36(\mid .23-1.51)$ & $1.50(1.33-1.69)$ \\
\hline CE & 690 & $226(32.8)$ & $0.65(0.55-0.77)$ & $0.91(0.72-1.15)$ \\
\hline SOE & 134 & $55(41.0)$ & $0.93(0.65-|.3|)$ & $1.49(0.95-2.32)$ \\
\hline SUE & 3695 & $1093(29.6)$ & $0.56(0.5 \mid-0.6 I)$ & $0.71(0.64-0.79)$ \\
\hline \multicolumn{5}{|l|}{ Sex } \\
\hline Male & 7474 & $2895(38.7)$ & Reference & Reference \\
\hline Female & 4589 & $1847(40.3)$ & $1.07(0.99-1.15)$ & $1.00(0.91-1.09)$ \\
\hline \multicolumn{5}{|l|}{ Age } \\
\hline $18 \sim 45$ & 773 & $269(34.8)$ & Reference & Reference \\
\hline $46 \sim 65$ & 4940 & $1942(39.3)$ & $1.21(1.04-1.42)$ & $0.79(0.68-1.02)$ \\
\hline $66 \sim 75$ & 3716 & I550 (4I.7) & $1.34(1.14-1.58)$ & $0.78(0.70-1.06)$ \\
\hline$\geq 76$ & 2634 & 981 (37.2) & I.II (0.94-I.32) & $0.70(0.56-0.86)$ \\
\hline \multicolumn{5}{|c|}{ Monthly household income, yuan } \\
\hline$\leq 500$ & 1384 & $503(36.3)$ & Reference & Reference \\
\hline $500-1000$ & 2793 & $|16|(4 \mid .6)$ & $1.25(1.09-1.42)$ & $1.05(0.90-1.23)$ \\
\hline $100 \mid-3000$ & 4033 & $1768(43.8)$ & $1.37(1.21-1.55)$ & $1.04(0.89-1.22)$ \\
\hline$\geq 3000$ & 815 & $402(49.3)$ & I.7I (I.43-2.03) & $1.27(1.03-1.57)$ \\
\hline Unknown & 3038 & $908(29.9)$ & $0.75(0.65-0.85)$ & $0.62(0.53-0.72)$ \\
\hline \multicolumn{5}{|l|}{ Types of health insurance } \\
\hline Own expense & 2305 & $799(34.7)$ & Reference & Reference \\
\hline Urban employee & 7293 & $3077(42.2)$ & $1.38(1.24-1.52)$ & $1.21(1.07-1.36)$ \\
\hline Rural cooperative & 2075 & $705(40.0)$ & $0.97(0.86-1.10)$ & $1.10(0.95-1.27)$ \\
\hline Commercial and other & 390 & $16 \mid(4 \mid .3)$ & $1.36(1.06-1.65)$ & $1.12(0.96-1.26)$ \\
\hline \multicolumn{5}{|l|}{ Hypertension } \\
\hline No & 3520 & $192(5.5)$ & Reference & Reference \\
\hline Yes & 8543 & $4550(53.26)$ & 19.75 (16.97-22.98) & 16.54 (I3.99-19.55) \\
\hline \multicolumn{5}{|l|}{ Diabetes } \\
\hline No & 8682 & $3211(37.0)$ & Reference & Reference \\
\hline Yes & 3381 & $|53|(45.3)$ & $1.41(1.30-1.53)$ & $1.10(1.01-1.20)$ \\
\hline \multicolumn{5}{|l|}{ Dyslipidemia } \\
\hline No & 5424 & 1678 (30.9) & Reference & Reference \\
\hline Yes & 6639 & $3064(46.2)$ & $1.91(1.78-2.06)$ & $1.61(1.48-1.76)$ \\
\hline \multicolumn{5}{|l|}{ Coronary artery disease } \\
\hline No & 10,357 & $4015(38.8)$ & Reference & Reference \\
\hline Yes & 1706 & $727(42.6)$ & $1.17(1.06-1.30)$ & $0.89(0.79-1.01)$ \\
\hline \multicolumn{5}{|l|}{ Atrial fibrillation } \\
\hline No & 10,875 & $4333(39.8)$ & Reference & Reference \\
\hline Yes & 1188 & $409(34.4)$ & $0.79(0.70-0.90)$ & $1.00(0.83-1.20)$ \\
\hline \multicolumn{5}{|l|}{ History of stroke } \\
\hline No & 7982 & $3036(38.0)$ & Reference & Reference \\
\hline Yes & 4081 & $1706(4 \mid .8)$ & $1.17(1.08-1.26)$ & $0.94(0.86-1.03)$ \\
\hline \multicolumn{5}{|l|}{ History of $\mathrm{AH}$ medication } \\
\hline No & 6430 & $1692(26.3)$ & Reference & Reference \\
\hline Yes & 5633 & $3050(54.2)$ & $3.31(3.06-3.57)$ & $1.08(0.98-1.19)$ \\
\hline \multicolumn{5}{|l|}{ SBP at discharge* } \\
\hline$<120 \mathrm{mmHg}$ & 649 & $99(2.1)$ & Reference & Reference \\
\hline $120-139 \mathrm{mmHg}$ & 2558 & $711(15.1)$ & $2.14(1.70-2.69)$ & $1.58(1.2 \mathrm{I}-2.05)$ \\
\hline $140-159 \mathrm{mmHg}$ & 4538 & $1727(36.6)$ & $3.4 I(2.73-4.26)$ & $\mathrm{I} .87(\mathrm{I} .45-2.4 \mathrm{I})$ \\
\hline$\geq 160 \mathrm{mmHg}$ & 4265 & $2176(46.2)$ & $5.79(4.63-7.23)$ & $2.65(2.06-3.42)$ \\
\hline
\end{tabular}

Note: *SBP at discharge data was missing for a total of 53 patients.

Abbreviations: $\mathrm{AH}$, antihypertensive; n, number; OR, odds ratio; TOAST, Trial of Org 10172 in Acute Stroke Treatment; LAA, large artery atherosclerosis; SAO, small artery occlusion; CE, cardioembolism; SOE, stroke of other determined etiology; SUE, stroke of undetermined etiology; SBP, systolic blood pressure. 
different TOAST subtypes. The doctors' decisions are only based on personal experience in clinical practice. Therefore, more evidence from clinical trials and recommendations from guidelines are needed for this decision.

Although current American Heart Association/American Stroke Association guidelines advocate that blood reduction is also reasonable for ischemic stroke patients without hypertension, ${ }^{1}$ our study showed that only $5.5 \%$ of nonhypertensive ischemic stroke patients were prescribed antihypertensive medications. This finding may reflect the influence of clinical trial results that suggest that nonhypertensive stroke patients may reap benefits from antihypertensive treatments. ${ }^{4}$ However, these agents may have been prescribed for other therapeutic reasons, such as using beta-blockers for heart rate control, or angiotensin-converting enzyme inhibitors for heart failure. ${ }^{5}$

\section{Acknowledgments}

CNSR was funded by the Ministry of Science and Technology and the Ministry of Health of the People's Republic of China (grant numbers: 2008ZX09312-008 and 2009CB521905). The current analysis of the CNSR data was supported by Beijing Novartis Pharma Co, Ltd (Beijing, China). In compliance with the Uniform Requirements for Manuscripts, established by the
International Committee of Medical Journal Editors, Novartis did not impose any impediment, directly or indirectly, on the publication of the study's results.

\section{Disclosure}

The authors report no conflicts of interest in this work.

\section{References}

1. Furie KL, Kasner SE, Adams RJ, et al; American Heart Association Stroke Council, Council on Cardiovascular Nursing, Council on Clinical Cardiology, and Interdisciplinary Council on Quality of Care and Outcomes Research. Guidelines for the prevention of stroke in patients with stroke or transient ischemic attack: a guideline for healthcare professionals from the american heart association/american stroke association. Stroke. 2011;42(1):227-276.

2. Wang Y, Cui L, Ji X, et al; China National Stroke Registry Investigators. The China National Stroke Registry for patients with acute cerebrovascular events: design, rationale, and baseline patient characteristics. Int J Stroke. 2011;6(4):355-361.

3. Adams HP Jr, Bendixen BH, Kappelle LJ, et al. Classification of subtype of acute ischemic stroke. Definitions for use in a multicenter clinical trial. TOAST. Trial of Org 10172 in Acute Stroke Treatment. Stroke. 1993; 24(1):35-41.

4. PROGRESS Collaborative Group. Randomised trial of a perindoprilbased blood-pressure-lowering regimen among 6,105 individuals with previous stroke or transient ischaemic attack. Lancet. 2001;358(9287): 1033-1041.

5. Ovbiagele B, Hills NK, Saver JL, Johnston SC. Antihypertensive medications prescribed at discharge after an acute ischemic cerebrovascular event. Stroke. 2005;36(9):1944-1947.
Patient Preference and Adherence

\section{Publish your work in this journal}

Patient Preference and Adherence is an international, peer-reviewed, open access journal focusing on the growing importance of patient preference and adherence throughout the therapeutic continuum. Patient satisfaction, acceptability, quality of life, compliance, persistence and their role in developing new therapeutic modalities and compounds to

\section{Dovepress}

optimize clinical outcomes for existing disease states are major areas of interest. This journal has been accepted for indexing on PubMed Central. The manuscript management system is completely online and includes a very quick and fair peer-review system. Visit http://www.dovepress.com/ testimonials.php to read real quotes from published authors. 